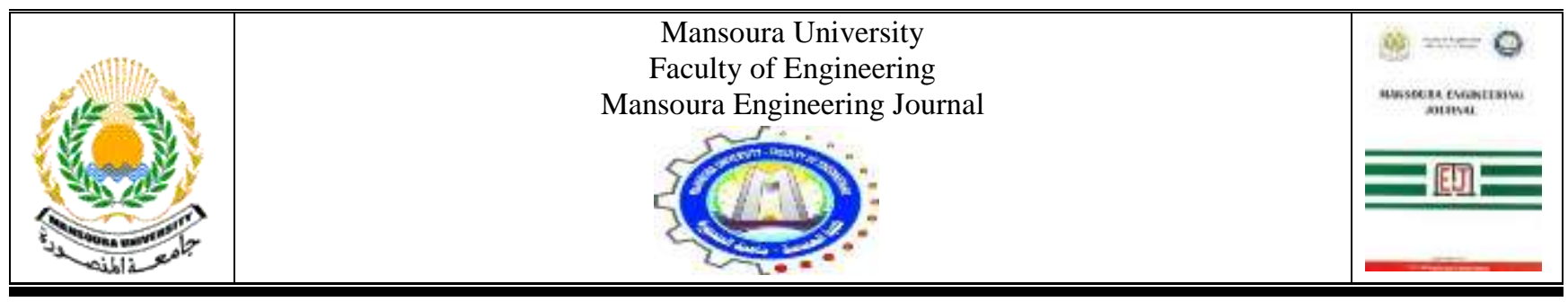

\title{
DC-DC converter as a maximum power point
} voltage tracker.

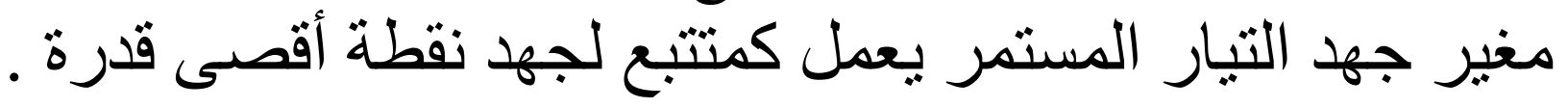

Eng.Ahmed Nori Alshawish, Assoc. Prof. Walaa Ibrahim Gabr, Prof. Saad Saad Eskander and Prof. Salah Ghazy Mohamed

KEYWORDS:
Solar energy;
Photovoltaic; maximum
power point tracing

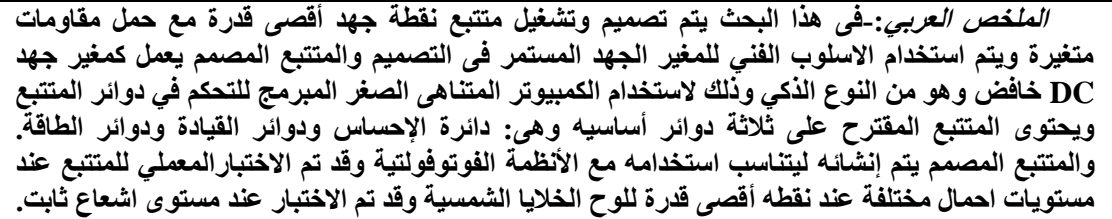

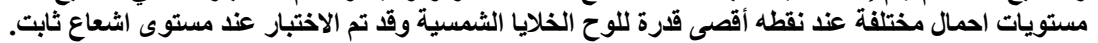

\begin{abstract}
In this paper, the maximum power point voltage tracker is designed and operated with the DC variable resistive load. The DC-DC converter technique is used for the design. The designed tracker operates as a DC-DC converter down. The designed tracker is a smart type; this is due to the use of programmed microcomputer to control the tracker circuits. The tracker contains three main circuits, sensing, drive and the power circuit. The designed tracker is constructed suitable to use with the photovoltaic power system (PVPS). The tracker is tested in the laboratory under different load levels at fixed insolation level.
\end{abstract}

\section{INTRODUCTION}

$\mathrm{T}$ WE rapid increase in the demand for electricity and the recent change in the environmental conditions such as global warming led to a need for a new source of energy that is cheaper and sustainable with less carbon emissions. Solar energy has offered promising results

Received: 1 November, 2017 - - Revised:10 January 2018 - accepted: 21 January 2018

Ahmed Nori Alshawish, Electrical Engineering, Azzawiya Oil Refining Company, Azzawiya, Libya, (e-mail: ahmednory2000@gmail.com).

Walaa Ibrahim Gabr, Electrical Engineering, Facility of Engineering, Banha University, Egypt

Saad Saad Eskander, Electrical Engineering, Facility of Engineering, Mansoura University,Egypt, (e-mail: drsaad eskander@yahoo.com).

Prof. Salah Ghazy Mohamed, Electrical Engineering, Facility of Engineering, Banha University, Egypt. in the quest of finding the solution to the problem. Harnessing solar energy using PV modules comes with its own problems that arise from the change in insolation conditions. These changes in insolation conditions severely affect the efficiency and output power of the PV modules [1-3]. A great deal of research has been done to improve the efficiency of the PV modules. A number of methods of how to track the maximum power point of a PV module have been proposed to solve the problem of efficiency and products using these methods have been manufactured and are now commercially available for consumers [1-3]. As the market is now flooded with varieties of these MPPT that are meant to improve the efficiency of PV modules under various insolation conditions it is not known how many of these can really deliver on their promise under a variety of field conditions. This research looks at how a different type of converter affects the output power of the module and investigates if the MPPT that are said to be highly efficient and do track the true maximum power point under the various conditions [1].

A MPPT is used for extracting the maximum power from the solar PV module and transferring that power to the load [4, 5]. A dc/dc converter (step up/ step down) serves the purpose of transferring maximum power from the solar PV module to the load. A dc/dc converter acts as an interface between the load and the module figure 2 [5]. By changing the duty cycle the load impedance as seen by the source is varied and 
matched at the point of the peak power with the source to transfer the maximum power [5]. Therefore, MPPT techniques are needed to maintain the PV array's operating at its MPP [6].

Many MPPT techniques have been proposed in the literature; examples are the Perturb and Observe $(\mathrm{P} \& \mathrm{O})$ methods [4, 6-9], and Incremental Conductance (IC) methods $[7,10]$.

The main aim of this paper is to design and construct the maximum point voltage tracker. In the thesis proposed design of the maximum power point voltage tracker (MPPVT) is ill lustrated. The proposed design is represented based upon the microcomputer. Hence, the designed tracker is a smart type. This chapter represents the design procedure at maximum power point voltage tracker. This taker can be used to stabilize the output voltage at any solar cell module with any type. The proposed designed tracker architecture is designed based upon the micro compute so; the proposed tracker is smart type. The designed tracker operates as the load

\section{PHOTOVOLTIC SYSTEM}

A Photovoltaic (PV) system directly converts solar energy into electrical energy. The basic device of a PV system is the PV cell. Cells are grouped to form arrays. The voltage and current available at the terminals of a PV device may directly feed small loads such as lighting systems and DC motors or connect to a grid by using proper energy conversion devices. This photovoltaic system consists of main parts such as PV module, charger, battery, inverter and load.

\section{A. Equivalent solar cell model}

A Photovoltaic cell is a device used to convert solar radiation directly into electricity. It consists of two or more thin layers of semiconducting material, most commonly silicon. When the silicon is exposed to light, electrical charges are generated. A PV cell is usually represented by an electrical equivalent one-diode model shown in Fig.1

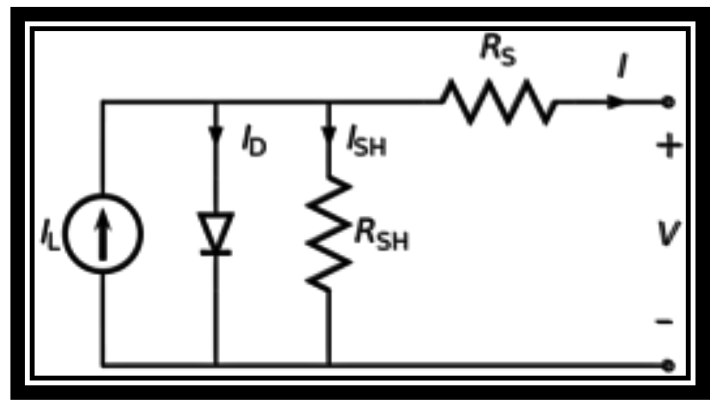

Fig.1. Solar cell model

The model contains a current source, one diode, internal shunt resistance and a series resistance which represents the resistance of each cell. The net current is the difference between the photo current and the normal diode current is given by equation [13].

$$
\begin{aligned}
& I D=I_{o}\left[e^{\frac{q\left(V+I R_{S}\right)}{K T}}-1\right] \\
& I=I_{L}-I_{o}\left[e^{\frac{q\left(V+I R_{S}\right)}{K T}}-1\right]-\frac{V+I R_{S}}{R_{S h}}
\end{aligned}
$$

Where

I is the cell current (A)

$q \quad$ is the charge of electron (coulomb)

$K \quad$ is the Boltzmann's constant $(\mathrm{j} / \mathrm{k})$

$T \quad$ is the cell temperature $(\mathrm{k})$

$I_{L} \quad$ is the photo current (A)

$I_{O} \quad$ is the diode saturation current. (A)

$R_{S}, R_{s h} \quad$ are cell series and shunt resistance (ohms)

$V \quad$ is the cell output voltage (v)

\section{PV SYSTEM WITH THE PROPOSED MAXIMUM POWER POINT VOLTAGE, TRACKER}

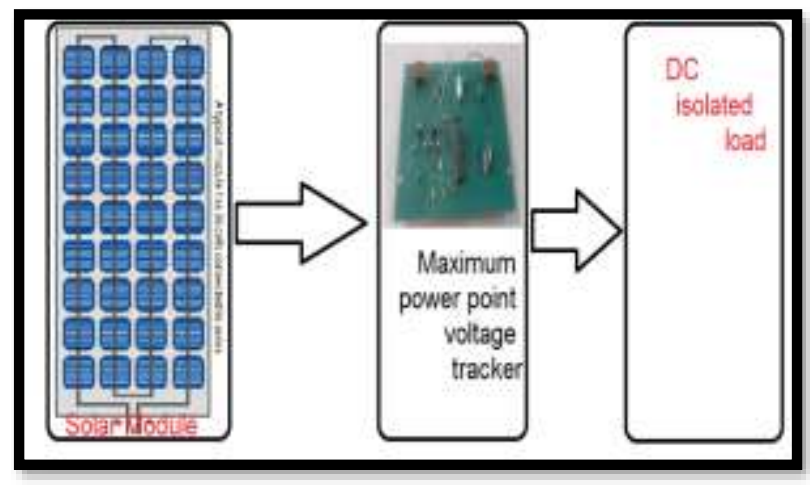

Fig. 2. Block diagram of PV system includes maximum power point voltage tracker

The PV solar cells array module used with the proposed maximum power point voltage tracker.

The system contains one of solar cells module has specifications of, maximum voltage $18.1 \mathrm{v}$, maximum power point current $8.26 \mathrm{~A}$, maximum power is $150 \mathrm{w}$ open circuit voltage is $21.6 \mathrm{v}$, and short circuit current is $9.1 \mathrm{~A}$. The PV solar cells module used is shown in figure 3 , is constructed of 36 cells connected in series.

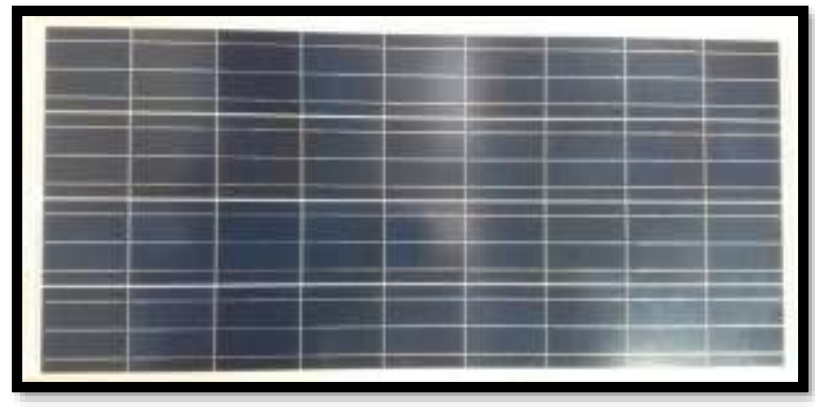

Fig. 3. Photo of solar cells module 


\section{DESIGN STRATEGY}

Initially, the selected module is tested in the laboratory for determining its electrical performance as well as to determine the maximum energy extracted from the module during the sunshine period. The module is oriented with tilt angle equal to the latitude angle, near $30^{\circ}$. The module is directed toward the equator during the test with fixed orientation angle.

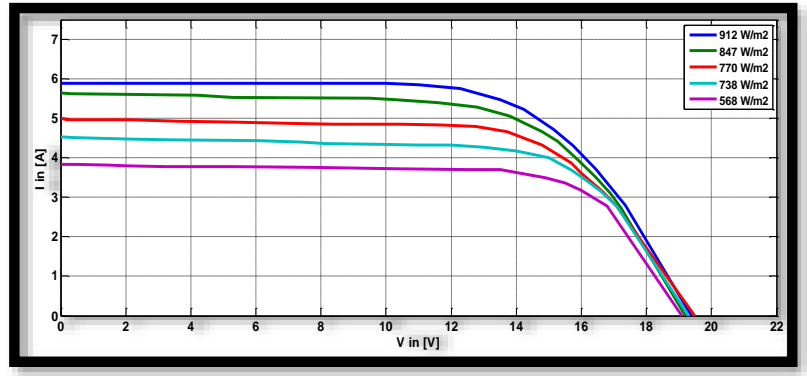

Fig.4. Electrical characteristics of PV module at different levels of insolation

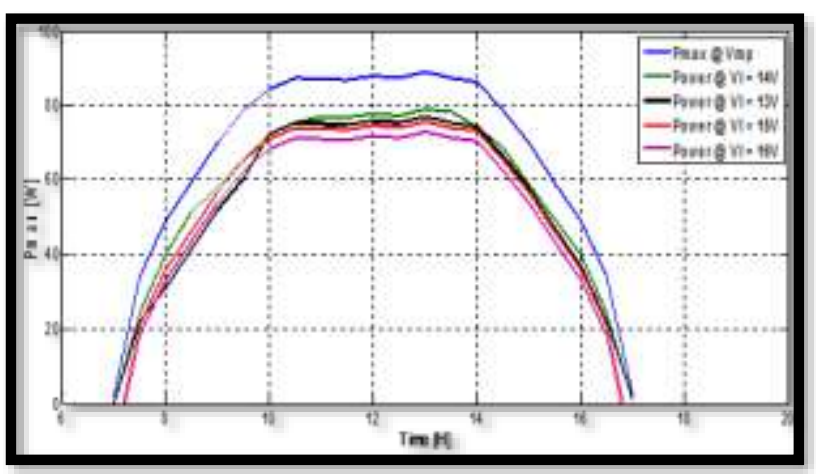

Fig.5. Maximum power extracted from the PV module at one day for different operating load voltages

The areas under the curves represent the energy output during one day at different operating voltage points of the loads locus in zone 2 . The energy output of the module at maximum power point voltage, $\mathrm{Vm}=14 \mathrm{~V}$ is $750 \mathrm{Whr}$.

On the other hand, it has values of 584, 557, 557.8and $531 \mathrm{Whr}$ at voltage levels of $14 \mathrm{~V}, 13,15$, and $16 \mathrm{~V}$. The load voltage level of $13 \mathrm{~V}$ locates in the first zone of the I-V characteristic of the tested module and the other levels $14 \mathrm{~V}$, 15 and $16 \mathrm{~V}$ locate at the second zone of the characteristic.

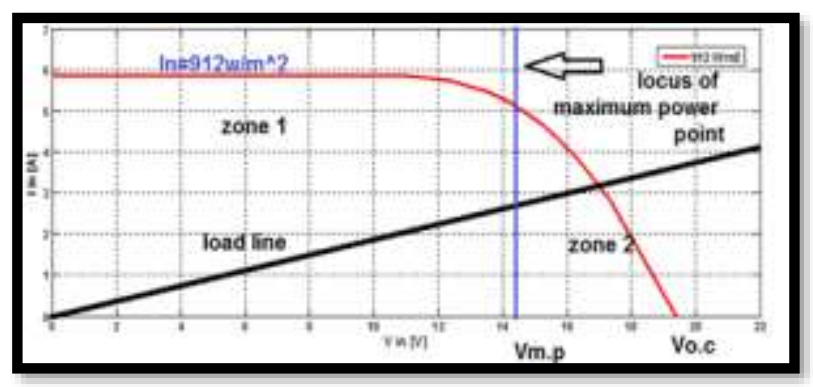

Fig.6. I-V Characteristic of tested module at in $=912 \mathrm{w} / \mathrm{m}^{\wedge} 2$

\subsection{Operation zone of designed maximum power point tracker}

Figure 6 illustrates the I-V characteristic of the module under test in solar energy laboratory at insolation level of 912 $\mathrm{w} / \mathrm{m} 2$.

The characteristic can be separated into two distinct zones. Zone 1 presents the part of the characteristic during which the voltage of the solar cells array is gradually reduced. On the other hand, the current of the module through this zone is nearly constant. Zone 2 illustrates the second part of the array voltage. During it the array voltage is nearly constant but the current is rapidly reduced.

The designed maximum power point voltage tracker is designed to operate in the second zone. consequently, all loads operate below the maximum power point voltage must be forced to return to the point of maximum power. The designed maximum power point voltage tracker operates to force the load to operate at maximum power point voltage.

The proposed tracker is operated in zone 2 because nearly all of loads operate during the later zone

\subsection{Control Method for The DC/DC Converter to get the PPT}

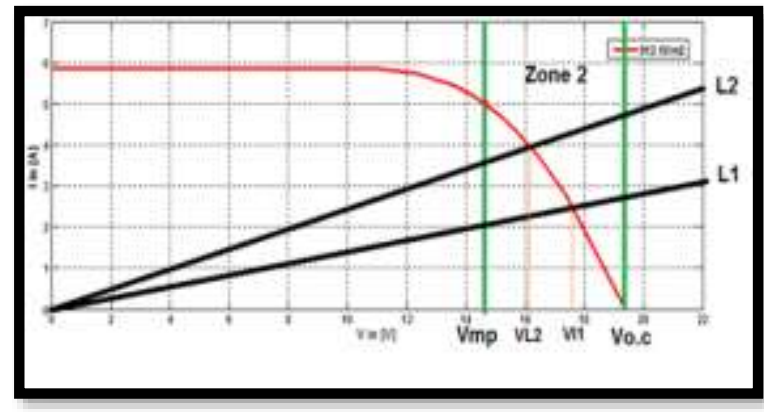

Fig. 7 Locus of two loads on I-V of solar cell module

Fig. 7 illustrates two distinct loads with different values supplied from the tested solar cells module. Load $\mathrm{L}_{1}$ supplies from the solar cell module at voltage $\mathrm{VL}_{1}$.

On the other hand, load $\left(\mathrm{L}_{2}\right)$ is provided its power from the

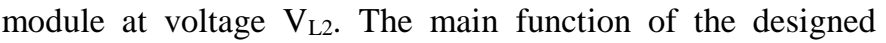
maximum power voltage tracker is to maintain the provided voltage to the loads constant at a value of Vmp.

Fig.8 represents that $V_{L 2}$ is taken less than $V_{L 1}$, while $V m p$ takes values less than $\mathrm{V}_{\mathrm{L} 1}$ and $\mathrm{V}_{\mathrm{L} 2}$

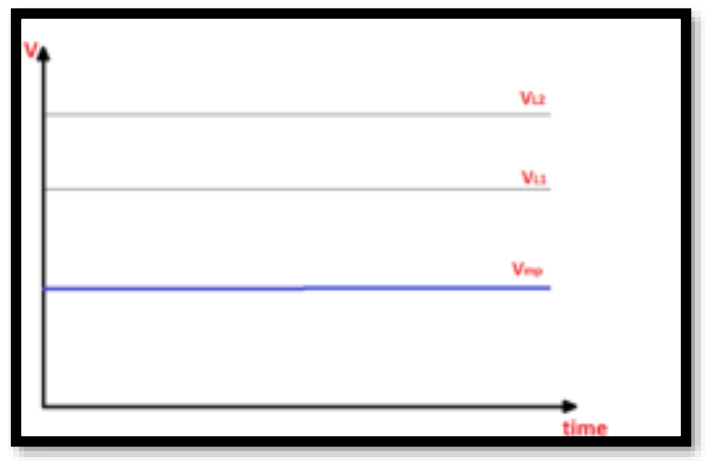

Fig. 8 Time levels of load voltage at different loads and at maximum power Vmp 
The operation of the designed tracker generates voltage pulses on the load terminals. Fig.9 illustrates the voltage pulses referred to the two levels selected of load voltage.

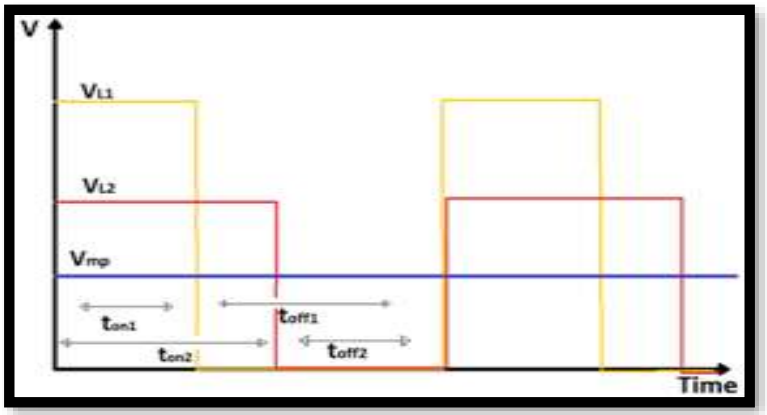

Fig.9. Pulses of tow load voltage generate by the designed tracker

Suppose that, load I upon the solar module has a level value of voltage $V_{L 1}$ such that $V_{L 1}>V m p$.

To toggle the voltage level $\mathrm{V}_{\mathrm{L} 1}$ to the selected value VMP, the voltage level $\mathrm{V}_{\mathrm{L} 1}$ must be cut to the train of pulses. The chopping frequency is selected as $500 \mathrm{~Hz}$ hence:

$V_{\mathrm{L} 1 \mathrm{av}}=V_{\mathrm{mp}}=\frac{V_{L 1} X t_{o n 1}}{T}$

Where $\frac{1}{T}=f_{\text {chopping }}$

Put $\frac{t_{\text {on } 1}}{T}=\mathrm{D}$

Where $\mathrm{D}$ is the duty cycle

$V_{\mathrm{mp}}=V_{L 1} \times D_{1}$

$V_{L 1}=\frac{V_{\mathrm{mp}}}{D_{1}}$

$V_{L 2}=\frac{V_{\mathrm{mp}}}{D_{2}}$

\section{Hence,}

$\mathrm{D}=\frac{V_{\mathrm{mp}}}{\mathrm{V}_{L}}$

Hence, the duty cycle is decreased as $\mathrm{V}_{\mathrm{L}}$ increased and so, the ON time of the power switch of the tracker is show in Figure 9.

\section{VALIDATION OF THE PROPOSED TRACKER}

The load voltage is recorded at the instant of fixed insolation. Different load levels are selected in the range of the second zone of the I-V characteristic (Fig. 6) for the tested module. The last zone represents the operation zone of the designed maximum power point voltage tracker. The output load voltage is a train of pulses with frequency about $500 \mathrm{~Hz}$.

The output voltage pulse contains steady part superimposed on it exist a pulse likes as a spike. The spike amplitude depends on the value of load resistance. The spike has duration depends upon the switch ON time of the power switch used. Figures 10 to 15 represent the output load voltage at the load terminals at different load levels, they show that, the spike depends on the load levels. As the value increases, the spike amplitude decreases. This is due to decreasing of the spike time constant as a result of increasing the load level

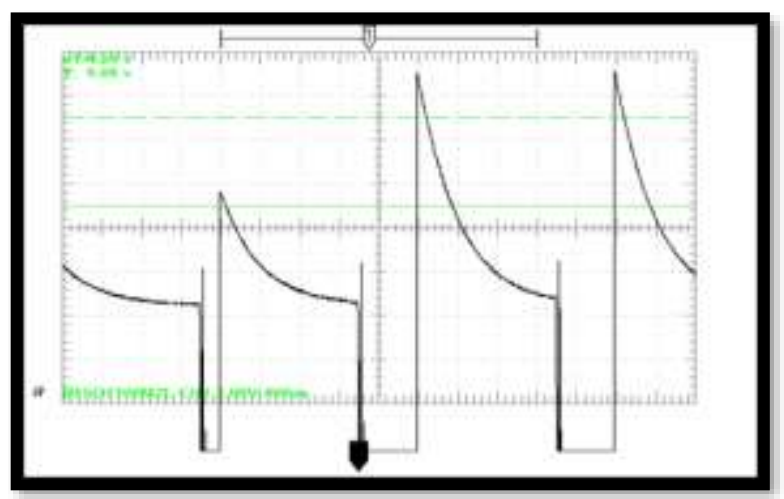

Fig. 10 Output plus at load terminal at load level L1

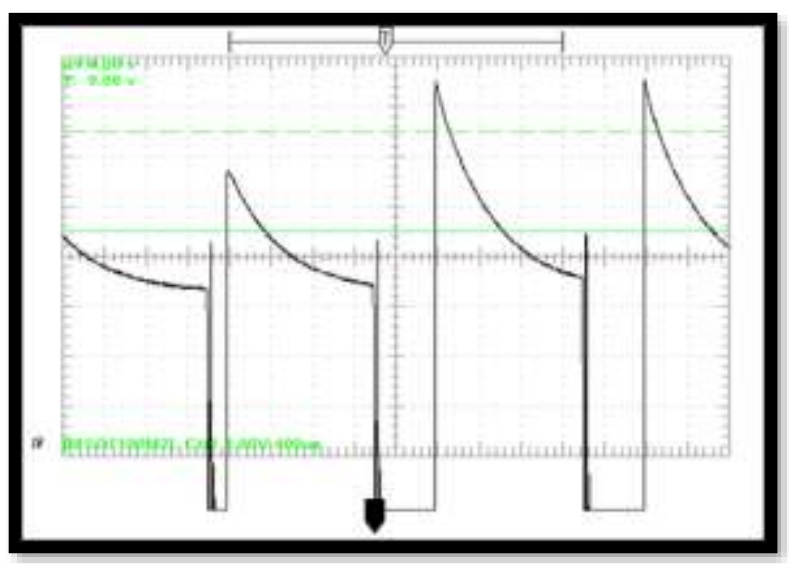

Fig. 11 Output plus at load terminal at load level L2

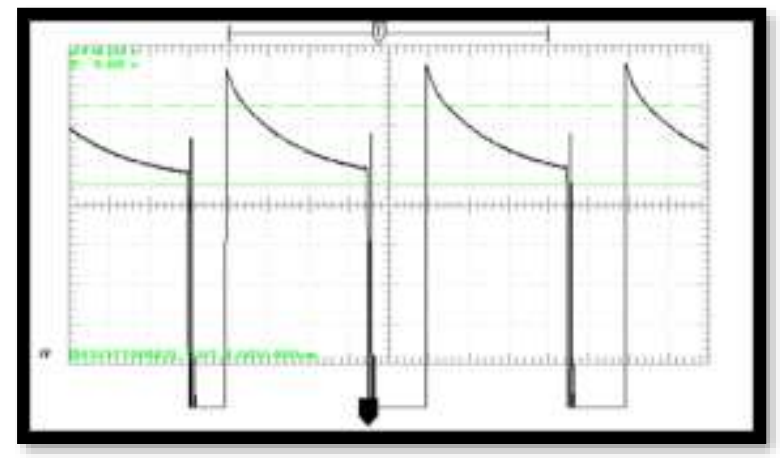

Fig. 12 Output plus at load terminal at load level L3

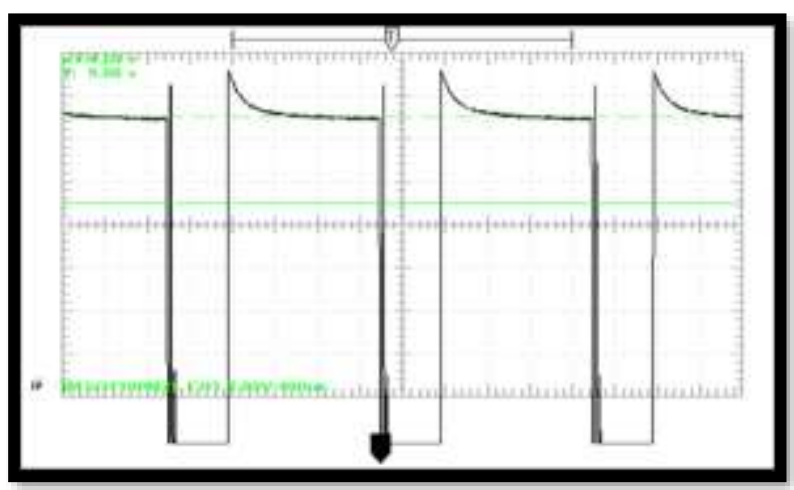

Fig. 13 Output plus at load terminal at load level L4 


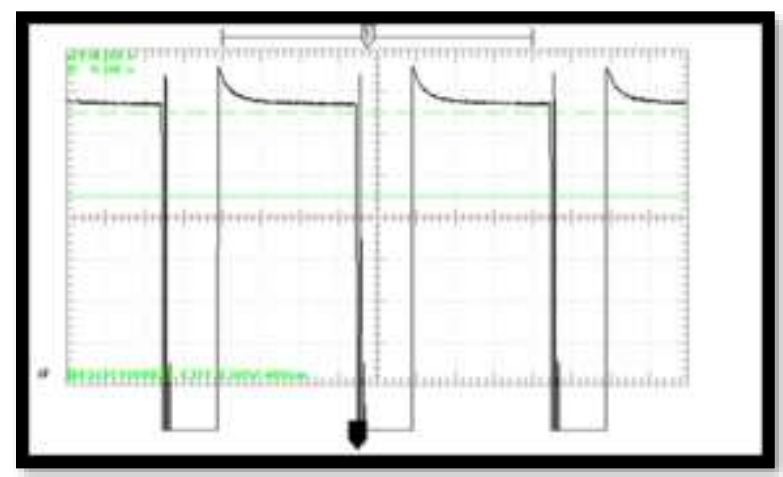

Fig. 14 Output plus at load terminal at load level L5

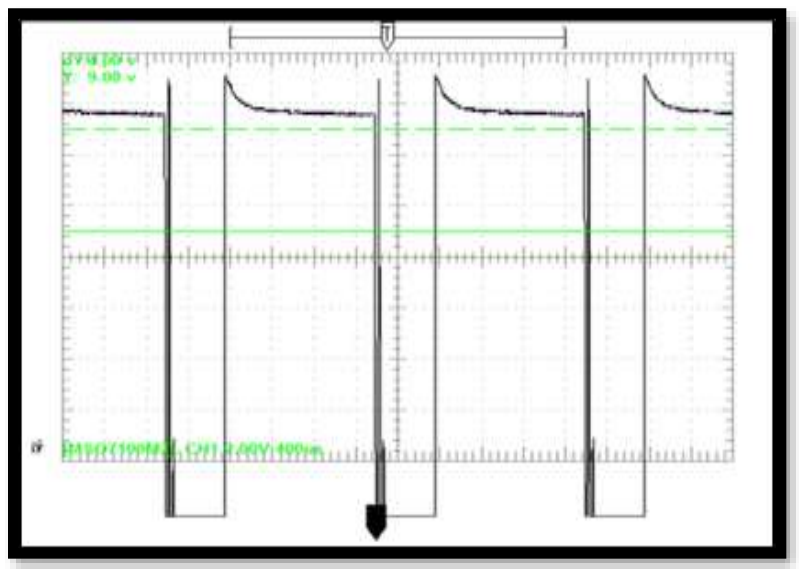

Fig. 15. Output plus at load terminal at load level L6

\section{ANALYSIS OF THE LOAD PULSES}

The load pulse depends upon the load level value as shown in the previous figures. Each pulse of the load contains two parts, a steady voltage level and a transient term in the form of a spike. The amplitude of the steady part is varied as the load level changes. The last amplitude is decreasing as the load increases in its level value

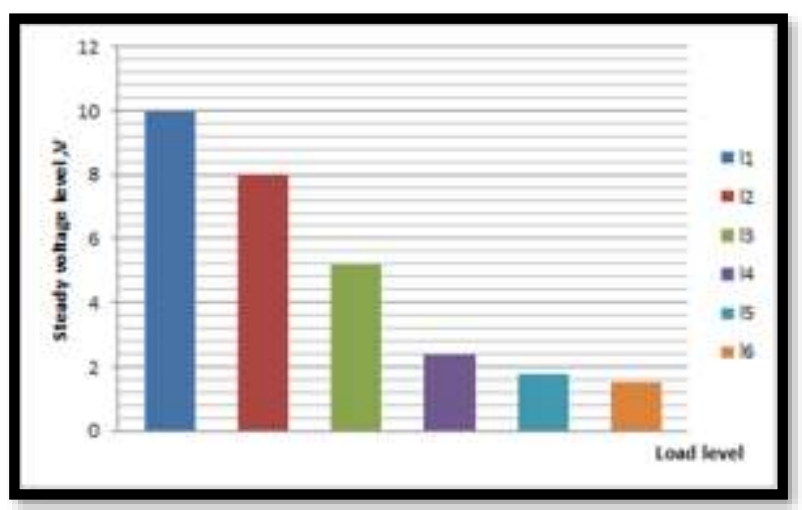

Fig. 16 Steady amplitude of the load voltage against load level

On the other hand, the spike amplitude superimposed on the steady voltage is directly proportional to the load level. Its amplitude decreases against the load value. This is due to the decrease of its time constant.

Figure 17 illustrates the relationships of the spike amplitude withe the load levels.

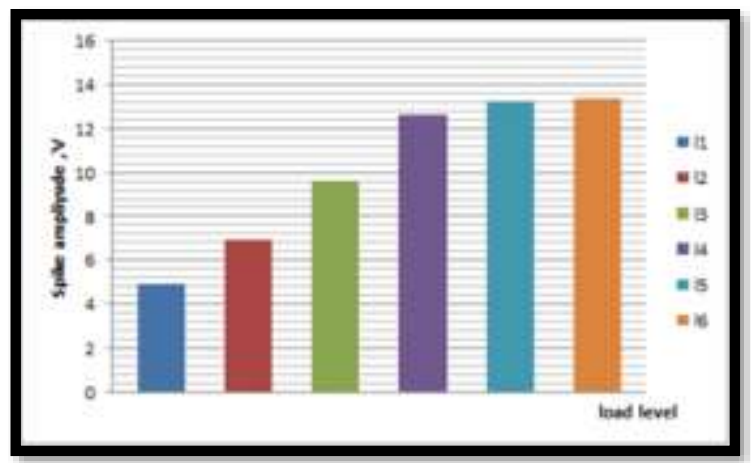

Fig. 17 Relationship between the spike amplitude and the load level.

\section{CONCLUSIONS}

This paper presents the use of DC-DC converter as a maximum power point voltage tracker. The operation strategy of the tracker is proposed survey of the designed tracker is illustrated the proposed designed maximum power point voltage tracker is experimentally tested. The test purpose is to show the validity of the designed tracker. The tracker relates to the solar cell module along with variable resistive load.

The tracker is designed to operate in the second zone of the l-V characteristic of the provided module. So, the variable range of the connected load is selected to force the tracker to operate in the selected operation region. The tracker operates at different load levels and at a fixed insolation level. Hence, no interval is selected as the best operation interval.

The load voltage is investigated at different load levels. The inspection of the load terminal voltage shows that it has a spike at the instant of closing the switch (switch on). This spike is attenuated by increasing the load level, this due to the decreases of the spike time constant. As the switch turns off, the spike voltage reaches the ground level. The experimental test of the tracker shows that, the maximum amplitude of the module terminal voltage equals to the maximum amplitude of the load voltage. The last two quantities are equal to the voltage at maximum power point of the module under test, thence the designed tracker is employed in the proper purpose.

\section{REFERENCES}

[1] R. S.Lewis, "Antartic Research and Relevant of Science," in Bulletin of the Atomic Scientists, vol. 26, 1970, pp. 2.

[2] Y.-H. Chang and C.-Y. Chang, "A Maximum Power Point Tracking of PV System by Scaling Fuzzy Control," presented at International Multi Conference of Engineers and Computer Scientists, Hong Kong, 2010.

[3] S.Mekhilef, "Performance of grid connected inverter with maximum power point tracker and power factor control," International Journal of Power Electronics , vol. 1, pp. 49-62, 2008.

[4] M.E.Ahmad and S.Mekhilef, "Design and Implementation of a MultiLevel Three-Phase Inverter with Less Switches and Low Output Voltage 


\section{E: 6 AHMED NORI ALSHAWISH, WALAA IBRAHIM GABR, SAAD SAAD ESKANDER, AND SALAH GHAZY MOHAMED}

Distortion," Journal of Power Electronics, vol. 9, pp. 594-604, 2009.

[5] S. Chin, J. Gadson, and K. Nordstrom, "Maximum Power Point Tracker," Tufts University Department of Electrical Engineering and Computer Science, 2003, pp. 1-66.

[6] R. Faranda and S. Leva, "Energy Comparison of MPPT techniques for PV Systems," WSES Transaction on Power Systems, vol. 3, pp.446-455, 2008.

[7] Vikrant.A.Chaudhari, "Automatic Peak Power Traker for Solar PV Modules Using dSpacer Software.," in Maulana Azad National Institute Of Technology vol. Degree of Master of Technology In Energy. Bhopal: Deemed University, 2005, pp. 98.

[8] T. P. Nguyen, "Solar Panel Maximum Power Point Tracker," in Department of Computer Science \& Electrical Engineering: University of Queensland, 2001, pp. 64.

[9] B. S, Thansoe, N. A, R. G, K. A.S., and L. C. J., "The Study and Evaluation of Maximum Power Point Tracking Systems," Internationalb Conference on Energy and Environment 2006 (ICEE 2006), pp. 17-22, 2006.
[10] C. S. Lee, " A Residential DC Distribution System with Photovoltaic Array Integration.," vol. Degree of Honors Baccalaureate of Science in Electrical and Electronics Engineering, 2008, pp. 38.

[11] T. Esram and P. L.Chapman, "Comparison of Photovoltaic Array Maximum Power Point Tracking Techniques," in 9. Urbana.

[12] E. I and O. Rivera, "Maximum Power Point Tracking using the Optimal Duty Ratio for DC-DC Converters and Load Matching in Photovoltaic Applications," IEEE, pp. 987-991, 2008.

[13] L. M. Tolbert, F. Z. Peng, T. G. Habetler, "Multilevel converters for large electric drives," IEEE Transactions on Industry Applications, vol. 35, no. 1, Jan./ Feb. 1999, pp. 36-44.

[14] K.Surya Suresh , M.Vishnu Prasad, "PV Cell Based Five Level Inverter Using Multicarrier PWM'International Journal of Modern E ngineering Research,Vol.1, Issue.2, 